\title{
Influences of Sense of Place on Farming Households' Relocation Willingness in Areas Threatened by Geological Disasters: Evidence from China
}

\author{
Dingde Xu ${ }^{1,2} \cdot$ Li Peng ${ }^{1} \cdot$ Shaoquan Liu ${ }^{1}$ Chunjiang Su${ }^{1} \cdot$ Xuxi Wang ${ }^{1,2} \cdot$ \\ Tiantian Chen ${ }^{1,2}$
}

Published online: 15 March 2017

(c) The Author(s) 2017. This article is published with open access at Springerlink.com

\begin{abstract}
Scholars from environmental psychology, geography, disaster science, and sociology have recently focused attention on evacuation and relocation behaviors and influencing factors in hazard-threatened areas. However, existing studies are mainly focused on developed countries and the influence of individual characteristics, household characteristics, and the perception of risk of urban households on evacuation and relocation behaviors. Few studies examine developing countries and the influence of farmers' sense of place in geological hazardthreatened areas. Using statistics of farming households in an area threatened by landslides, this is a pilot study to explore the relationship of sense of place to the relocation willingness of farming households while controlling for other variables. The results show that: (1) Households with higher scores of place identity and place dependence are less willing to relocate, whereas place attachment has no significant relationship to household relocation willingness; (2) Risk perception dimensions, including probability, threat, and controllability have a significant relationship to household relocation willingness, while worry and fear of the unknown have no significant relationship; (3) Household characteristics, including income, whether a household has experienced economic loss from landslides, and social support are significantly correlated with household relocation willingness, while gender, age, experience, distance to hazard sites, size of household, children, older
\end{abstract}

Li Peng

pengli@imde.ac.cn

1 Institute of Mountain Hazards and Environment, Chinese Academy of Sciences, Chengdu 610041, China

2 University of the Chinese Academy of Sciences, Beijing 100049, China people, and housing material are not. The results for information and education are not robust. This study contributes to the current literature by improving the understanding of the relationship of sense of place to the relocation willingness of farming households in villages threatened by geological disasters in rural China.

Keywords China $\cdot$ Farming households $\cdot$ Relocation willingness $\cdot$ Risk perception $\cdot$ Sense of place $\cdot$ Three Gorges Reservoir area

\section{Introduction}

Scholarly research on household evacuation and relocation behaviors in areas threatened by natural hazards can be found in the fields of environmental psychology, geography, disaster science, sociology, and others. Clarifying household evacuation and relocation behaviors and the reasons behind them can provide a reference for the formulation of disaster preparedness and mitigation policies, so as to reduce loss of life and property. Most previous studies, however, have centered on developed countries (such as the United States and Canada) (Tobin et al. 2011; Durage et al. 2014; Lazo et al. 2015) and are primarily concerned with urban household response to hurricanes, floods, and other natural disasters (Lim et al. 2016), while few studies examine developing countries and the response of rural households in poor areas to geological disasters. Although compared to other natural disasters the impact of landslides does not appear to be particularly high, it is evident that the number of disasters associated with landslides is increasing worldwide (Alcántara-Ayala 2009; Hernández-Moreno and Alcántara-Ayala 2016). According to the EM-DAT Database, 644 landslide disaster events 
were registered globally between 1965 and 2014, involving 40,263 deaths and about 9.5 million affected people (CRED 2015).

The hill and mountain areas in China occupy close to $69 \%$ of China's total land area and are home to $45 \%$ of its population (Chen et al. 2007; Xu et al. 2015a, b; Cao et al. 2016). Due to the socioeconomic development in mountainous areas, natural hazards, such as earthquakes and landslides, are having increasingly more impact in recent decades. As a result, many farming households who had managed to overcome poverty return to that condition. According to the statistics, in 2016, China experienced 9710 cases of geological disasters, and landslides accounted for $76.2 \%$ of the total geological disasters. Meanwhile, the geological disasters caused 370 deaths, 35 people missing, 209 people injured, and a direct economic loss of 3.17 billion Yuan (USD 460 million) (Geological Disaster Emergency Response Directing Center of Ministry of Land and Resources 2016). Because of geological disaster, economic loss, and extreme climate, the average return-topoverty rate in the western part of China stands at 15-25\%, with some places reaching as high as $30-50 \%$ (Yao and $\mathrm{Xu}$ 2013). One of the largest recent disasters, the Zhouqu landslide and mudslide in 2010, led to 1765 deaths, impacting 2.1 million people and resulting in USD 759 million of economic loss (CRED 2015). Thus, a focus on the relocation behavior of farming households in landslidethreatened areas has become a necessity.

Knowing who is at higher risk for not evacuating/relocating, and why, can help policymakers target policy to reduce loss of lives and property. Therefore, exploring the significant factors that affect the relocation behavior of households has become a key research focus in academic circles. However, the existing research focuses primarily on the influence of individual characteristics (gender, age, education, and so on) (Whitehead et al. 2000; Tobin et al. 2011; Huang et al. 2012; Durage et al. 2014; Lazo et al. 2015; Lim et al. 2016), household characteristics (household size, income, house ownership, and so on) (Baker 1991; Bateman and Edwards 2002; Dash and Gladwin 2007; Durage et al. 2014; Wallace et al. 2014), risk perception (Perry 1979; Houts et al. 1984; Riad et al. 1999; Stein et al. 2010; Lazo et al. 2015), source of warnings (Wilmot and Mei 2004; Widener et al. 2013; Lazo et al. 2015; Lim et al. 2016), social support (Perry et al. 1981; Riad et al. 1999; Adeola 2008), previous experience of hazards (Lindell et al. 2005; Burnside et al. 2007; Adeola 2008; Lazo et al. 2015), and access to resources (Riad et al. 1999; Lim et al. 2016) on the relocation/evacuation behavior. All of these factors can only partly explain residents' relocation behaviors, but do not explain well one factor that has played a role in recent extreme events in China: although knowing there is a continuing threat in residential areas after a disaster, some households still choose in situ reconstruction and are reluctant to relocate (Long and Zou 2010).

The reasons for this phenomenon may lie in two key aspects: sustainable livelihoods and sense of place formed by long-term interaction between people and specific places. As a concept of environmental psychology and human geography, sense of place is based on the subjectivity of human experiences of places, and connotations including local characteristics, as well as peoples' feelings, dependence, and identity of place (Eyles 1985), embodying the human-land relationship based on the interaction of environmental resources, culture, society, and other factors (Tuan 1979). In this study, sense of place was defined as a multidimensional construct comprising: (1) beliefs about the relationship between self and place; (2) feelings toward the place; and (3) the behavioral exclusivity of the place in relation to alternatives (Jorgensen and Stedman 2001). Sense of place provides a new perspective for understanding the phenomenon of relocation that households face with the threat of geological disasters. The concept of sense of place has been discussed for many years, and there are extensive studies of the influence of sense of place on household behaviors. However, most of these studies focus on the field of recreational geography, paying more attention to visitors' attachment to recreation and tourist destinations. Only a few studies are concerned with the relationship between households' sense of place and their behavior choices in hazard-threatened areas (Mishra et al. 2010). In these studies, scholars focus primarily on the relationship between attachment to place and disaster preparedness (Paton 2001; Mishra et al. 2010). Although some studies have suggested that bonds with place would affect disaster preparedness and relocation (Gaillard 2008; Carroll et al. 2009), most of these studies are qualitative; quantitative studies exploring the relationship between sense of place and household relocation behaviors are less available. Thus, this is a pilot study to explore the relationship of sense of place to the relocation behavior of farming households while controlling for other variables. This study will improve our understanding of household relocation behavior and factors informing that behavior, and provide a reference for corresponding policy making.

The Three Gorges Reservoir area is a typical mountainous region subject to frequent geological disasters. It has high poverty and return-to-poverty rates. This study is based on statistics from farming households in the area and explores the significance of sense of place with respect to these households' relocation willingness, so as to inform disaster prevention policies.

\subsection{Literature Review}

Research on residents' relocation activities in disasterthreatened areas and disaster impacts can be traced back to 
the 1950s (Perry et al. 1981). Early studies tended to be scattered (Mileti et al. 1975; Drabek 1986). It was not until Baker (1991) summarized the results of 15 empirical studies, conducted from 1960 to 1990, that identified variables affecting household hurricane relocation/evacuation, that such research started to be more systematic (Huang et al. 2016). The majority of scholars began to adopt variables in their research as their hypothesis basis (Riad et al. 1999; Lindell et al. 2005; Adeola 2008; Huang et al. 2012) and constantly added other potential impacting factors of residents' relocation/evacuation activities (for example, forecasting, warning integration, and so on). However, most of the results had deviations from each other. Some scholars focus on residents' actual relocation/ evacuation actions; while others focus their attention on residents' relocation/evacuation activities under hypothetical hurricane scenarios (the relocation/evacuation willingness under hypothetical conditions). The latter can be further divided into voluntary relocation/evacuation and forced relocation/evacuation under government order. Even though some scholars indicate that relocation/evacuation willingness under hypothetical conditions is significantly correlated with actual relocation/evacuation activities (Kang et al. 2007), differences still exist between forced relocation, voluntary relocation, and actual relocation. Forced relocation will probably result in conflicts between residents and the government, and lead to negative impacts in community management (Tobin and Whiteford 2002). More evidence is needed on the significance of relocation/evacuation willingness (Huang et al. 2016). Huang et al. (2016) examined 38 studies involving actual responses to hurricane warnings and 11 studies involving expected responses to hypothetical hurricane scenarios conducted since 1991. Similar to the studies of Baker (1991) and Huang et al. (2016), this study focused on the influence of households' individual characteristics (including previous experience of hazards), household characteristics (including source of information, social support, and so on), and risk perception on their relocation willingness. A brief literature review is undertaken to assist in developing our research hypotheses.

\subsection{Individual Characteristics and Relocation/ Evacuation Willingness}

Previous research has suggested that individual characteristics, including gender, age, education, and previous experience, are significant factors that affect household relocation/evacuation willingness, but empirically the evidence has been mixed (Huang et al. 2016). Some studies have shown that females are significantly more likely than males to reloacte/evacuate (Whitehead et al. 2000; Bateman and Edwards 2002; Lazo et al. 2015; Lim et al. 2016), although Stein et al.'s (2013) study showed that gender had no significant impact on household evacuation willingness. Some studies have shown that older residents are more likely to relocate/evacuate than other age groups (Lazo et al. 2015), but others have found the opposite effect (Kaniasty and Norris 1995; Trumbo et al. 2014; Lazo et al. 2015) or no effect (Huang et al. 2012; Stein et al. 2013). A few studies have shown that individuals with higher educational levels were more likely to relocate/evacuate than others (Hasan et al. 2011), as well as revealing other differences in evacuation decision making (Whitehead et al. 2000; Stein et al. 2013; Lazo et al. 2015; Lim et al. 2016). Some studies have shown that prior experience in disaster situations was slightly significant in predicting the probability of evacuation (Bateman and Edwards 2002; Burnside et al. 2007; Adeola 2008; Lazo et al. 2015), while other studies found a negative or no significant relationship between past experience and relocation/evacuation willingness (Lindell et al. 2005; Lazo et al. 2010).

\subsection{Household Characteristics and Relocation/ Evacuation Willingness}

In addition to individual characteristics, a few studies have shown that household characteristics, including income, household size, household composition, housing material, proximity to the hazard, source of warning information, and social influence, were also significant factors that affected households' relocation/evacuation willingness, but empirically the findings were not unequivocal. Some studies have found that relocation/evacuation likelihood increased with income (Bateman and Edwards 2002; Dash and Gladwin 2007), decreased with income (Trumbo et al. 2014), or was insensitive to income (Whitehead et al. 2000; Huang et al. 2012; Stein et al. 2013; Yang 2016). Lazo et al. (2015) found that household size had no significant impact on household evacuation willingness. Durage et al. (2014) showed that households with more members were more concerned and made quicker decisions on evacuation than one- or two-person households. With respect to household composition, having children may help motivate relocation/evacuation (Bateman and Edwards 2002; Lindell et al. 2005; Peacock et al. 2005; Dash and Gladwin 2007; Lim et al. 2016), or impede relocation/evacuation (Baker 1991; Lindell and Perry 2012; Stein et al. 2013; Wallace et al. 2014). Housing material indicated the capacity of the household to cope with disasters-households with concrete homes showed a higher probability of staying at home when compared to others whose houses were made of wood (Lim et al. 2016).

With respect to the proximity to the hazard, it was generally acknowledged that households were more likely to relocate/evacuate when the home is closer to the hazard 
site (Wilmot and Mei 2004; Lindell et al. 2005), although some studies showed an opposite result (Lim et al. 2016). Some studies found that warning information from authorities had a significant positive impact on household evacuation willingness (Wilmot and Mei 2004; Burnside et al. 2007; Lazo et al. 2015; Lim et al. 2016). Other studies found that warning information from a family member or friend also had a significant impact on household evacuation willingness (Lazo et al. 2010; Widesner et al. 2013), while some studies did not (Lazo et al. 2015). Dash and Gladwin (2007) found that people were more likely to evacuate if they heard the warning in person from a family member, friend, or authority figure, rather than just from the media; thus, social influence was an important variable to predict the evacuation willingness of households. Social networks not only relate to information about a disaster, but are also related to the sharing of resources and enhancing the ability of groups to resist external risk (Xu et al. 2015a, b; Xu et al. 2017). Tierney (2013) showed that people look to others for help with the evacuation decisionmaking process. Households with stronger perceived social support were far more likely to evacuate than those with weaker perceived social support, but network size did not predict evacuation (Riad et al. 1999).

\subsection{Risk Perception and Relocation/Evacuation Willingness}

Risk perception also has a significant relationship to households' relocation/evacuation willingness. Disaster warnings alone to households did not motivate relocation/ evacuation-people must perceive risk (Dash and Gladwin 2007). Several studies found that perceived risk was a primary factor in disaster relocation/evacuation decision making (Baker 1991; Whitehead et al. 2000; Stein et al. 2010; Huang et al. 2012). Some studies have shown that measures of perceived severity and susceptibility were significantly related to relocation/evacuation (Houts et al. 1984; Riad et al. 1999), while in Lazo et al.'s (2015) study catastrophic potential and risk controllability had no significant impact on household relocation/evacuation willingness. Another model proposed by Perry (1979) in a review of empirical work suggested that individuals assess personal risk by examining the proximity, certainty, and severity of the threat. In some post-event studies, some evacuees reported that they simply felt safe in their home or where they were (Dow and Cutter 2000).

\subsection{Sense of Place and Evacuation/Relocation Willingness}

The concept of sense of place has been studied for many years, but studies of households' sense of place and their willingness to relocate/evacuate in hazard-threatened areas are relatively few (Mishra et al. 2010). In these studies, scholars focus primarily on the relationship between place attachment and disaster preparedness (Paton 2001; Mishra et al. 2010), and the findings are not unequivocal. Paton (2001) found that community attachment and preparedness had a weak relationship, while in Mishra et al.'s (2010) study place attachment was found to significantly influence flood preparedness. However, sense of place is different from sense of community attachment. Sense of place emphasizes the identity, dependence, and attachment to the place, which is the result of interaction between people and land. Community attachment represents the extent and pattern of social participation and integration into the community, and the sentiment toward the community, and is often measured by the variable of community residents' dwelling time. Some, mostly qualitative, studies have suggested that place attachment affects disaster evacuation (Kiecolt and Nigg 1982; Gaillard 2008; Carroll et al. 2009) as well as residents' willingness to return (Porter 2015). Quantitative studies that explore the relationship between sense of place and residents' relocation willingness are less available.

\subsection{Research Hypotheses}

Based on the gaps in the existing literature and a comprehensive consideration of the actual situation of the Three Gorges Reservoir area, this study examined factors that may affect household relocation willingness from four aspects-individual characteristics (including previous experience), household characteristics (including source of information, social support, and so on), risk perception (including five dimensions: possibility, dread, fear of the unknown, controllability, and threat), and sense of place (including three dimensions: place identity, place dependence, and place attachment) — to explore the following research hypotheses:

H1 Households with higher scores on sense of place (place identity, place dependence, and place attachment) are less likely to relocate.

H2 Households with a higher perception of probability, threat, worry, and fear of the unknown are more likely to relocate; households with a higher perception of controllability are less likely to relocate.

H3 Females, older residents, and individuals with higher educational levels are more likely to relocate; individuals with prior experience are less likely to relocate.

H4 Household characteristics-including income, social support, whether a household has experienced 
economic loss from landslides, distance to hazard site, source of information, size of household, children, the elderly, and housing material are all significantly correlated with household relocation willingness, but the direction of the influences are unknown.

\section{Data and Methods}

The Three Gorges Reservoir area (Fig. 1) comprises 19 county-level administrative areas affected by the inundation resulting from the Three Gorges Project. The area, totaling $54,200 \mathrm{~km}^{2}$, is an important part of the upper reaches of the Yangtze River economic zone. At the end of 2014, arable land accounted for $40 \%$ of the land area, at a per capita average of $0.005 \mathrm{ha}$, which is lower than the national average (0.007 ha). Of the total population, $60 \%$ work in agriculture, although agricultural income accounts for only $19.8 \%$ of total revenue. The narrow strip of land is very densely populated, which leads to social tension and overexploitation of the environment. There are significant differences in economic development between the county-level administrative areas. Eight are listed as key national poverty-alleviation counties (Peng et al. 2017). The per capita net income of the rural residents is 8441 Yuan (USD 1379), 14.69\% lower than the national average for the rural population (Chongqing Municipal Bureau of Statistics 2015; CNSB 2015). In addition, due to the limitation of terrain, many rural settlements in the Three Gorges Reservoir area are located in geological hazard-threatened areas, and some settlements are even located at sites where geological hazards have occurred before (for example, debris flow fans).

\subsection{Data Source}

This study mainly used data from a survey conducted in August 2015 in the Three Gorges Reservoir area. The
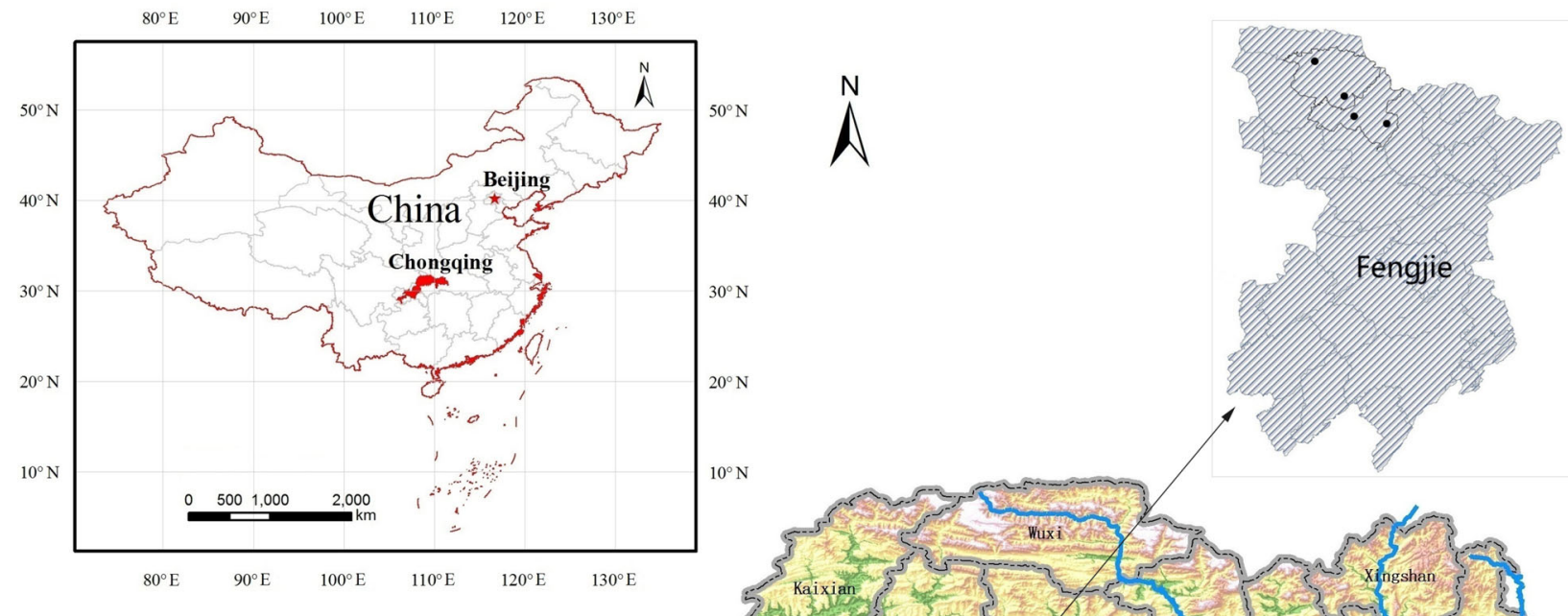

Legend

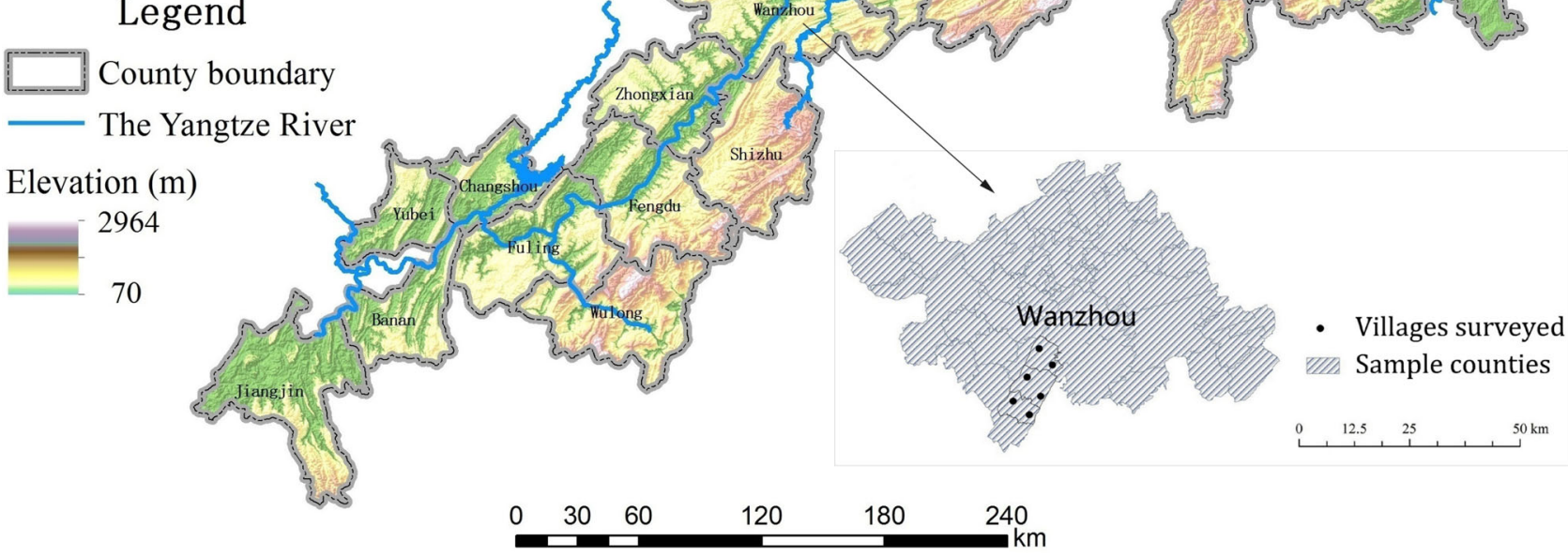

Fig. 1 Location of the sample counties and villages in the Three Gorges Reservoir area of China 
investigation largely focused on the situation of farming households in 2014, regarding relocation willingness, individual characteristics, household characteristics, risk perception, and sense of place. When a storm is coming, the government will send warning in advance and professional disaster-monitoring personnel will constantly track and focus on the threatened geological areas. When there is a sign of hazard occurrence-for example, abnormal sounds in rocks-the government will release a compulsory evacuation order asking local residents at risk to move to designated shelters such as village committee buildings and schools. Each survey questionnaire took approximately $1 \mathrm{~h}$ to complete for an average respondent. The survey sample was selected using a combination of stratified sampling and equal-probability random sampling.

The focus of this research is to explore the influences of sense of place on the relocation willingness of farming households. Considering the variations in geology, populations at risk, and economic development levels, this study classified the 19 counties into two categories-those with more threatened people and low economic development level (11 counties); and those with fewer threatened people and high economic development level (8 counties). One county was randomly selected from each category, resulting in two sample counties: Wanzhou from the group of fewer threatened people and high economic development level and Fengjie from the other group, which together include 48 townships. Considering the number of farming households threatened, as well as the economic development level in the geological disaster threatened area, we selected three and two townships (with 11, 5, 5, 8, and 8 villages), respectively, from Wanzhou and Fengjie. According to the number of farming households who are threatened by geological disaster on the lists provided by the village cadres, we divided the 37 villages into high geological disaster threat villages and low geological disaster threat villages, then randomly picked one village from each group in every township. One of our sample townships has 11 villages. Considering the representativeness of the samples, we randomly picked one more high geological disaster threat village from this sample township. Finally, we obtained 11 sample villages. In the 11 sample villages, according to the geological disaster threat lists (on which a total of 2055 farming households were identified as threatened), we selected 20-40 threatened households from each for the survey. Ten investigators with professional training background each conducted household questionnaire surveys in 2-4 households per sample village. Eventually, 348 valid questionnaires were generated with a completion rate of $100 \%$. They showed that 252 households under threat did not suffer a disaster, while 92 households did. The locations of the sample counties and villages are shown in Fig. 1.

\subsection{Method}

Research methods in this study can be divided into two parts. First, the theoretical framework of this study is introduced. Second, we set up the measurement econometric models suitable for farming households in the western mountainous areas of China.

\subsubsection{Theoretical Framework}

Few theoretical frameworks relating to household relocation willingness in geological hazard-threat areas have been developed. The best known of these is the protective action decision model (PADM), proposed by Lindell et al. (2005) and Lindell and Perry (2012). The essence of PADM is that households' perception of disaster risks (especially the threat perception) will affect their decision making, while households' perception of disaster risks is also affected by the stimulus of the external environment (environmental cues, social cues, and so on), the generation and transmission of information (information sources, warning messages, information channel access and preference, and so on), individual characteristics (gender, age, education, prior experience, and so on), and household characteristics (children, older people, income, household size, housing material, and so on). Thus, residents perceive risks, and make appropriate behavioral decisions (such as relocation) after comprehensive consideration of situational motivations (incentives/benefits) and situational barriers (constraints/costs).

Although PADM is a relatively mature framework, it does not consider the effect of sense of place on residents' relocation behaviors. Based on the PADM framework, this study introduces sense of place and attempts to explain households' relocation willingness from this new perspective.

\subsubsection{Selection and Definition of the Model Variables}

In this section, we first introduce the measurement of the dependent variable (households' relocation willingness), followed by the measurement of our focus variables (sense of place). Finally, we introduce the measurement of other control variables.

1. Measurement of relocation willingness

The dependent variable of the research is households' willingness to relocate in landslide threat areas. Households' willingness to relocate under government order was measured, and divided into: $1=$ strongly unwilling, $2=$ unwilling, $3=$ neutral, $4=$ willing, $5=$ strongly willing. In this study, households' willingness to relocate under the government's order 
indicates households' willingness to permanently move away from the original residences (threatened by landslide disasters) to safe areas. This kind of permanent relocation is different from evacuation under imminent threat of a hazard or temporary relocation under potential threat. The former can fundamentally solve the problem of the threat of geological disasters faced by farming households. However, the latter two cases-evacuation in the event of geological disasters to emergency shelters, and temporary relocation under potential threat of disasters (such as during torrential rains) that may or may not become permanent-do not imply the same level of permanency.

2. Measurement of sense of place

(The objective of this study is to explore the relationship of sense of place to the relocation willingness of peasant households while controlling for individual characteristics, household characteristics, and risk perception. The measurement of sense of place draws from Jorgensen and Stedman's (2001) classic study. Sense of place is divided into three dimensions - place identity, place attachment, and place dependence, and on this basis, items were designed to measure the various dimensions of sense of place. Because the subjects of the research are farming households in poor mountainous areas in Western China with generally low levels of education, and Jorgensen and Stedman's (2001) measurement items of sense of place are relatively abstract, some key items were revised and five households in landslide threat areas in Wanzhou County were selected to conduct the pre-research, to ensure that the farming households could understand the revised measurement items of sense of place (Table 1).

3. (3) Measurement of control variables

Drawing from the research of Slovic (1987), Flynn et al. (1994), Riad et al. (1999), Whitehead et al. (2000), Bateman and Edwards (2002), Lindell et al. (2005), Burnside et al. (2007), Adeola (2008), Huang et al. (2012), Lazo et al. (2015), Lim et al. (2016), Xu et al. (2016) and Xu et al. (2017), this study set the factors that influence household relocation willingness, dividing the control variables into individual characteristics, household characteristics, and risk perception. For the specific definition and measurement of these variables, see Table 2. The measurement of risk perception refers to the study of Xu et al. (2016), including five dimensions-probability, worry, fear of the unknown, controllability, and threat. Other indicators that can reflect households' demographic characteristics or characterize households' livelihood assets are subdivided into individual characteristics and household characteristics.
Specifically, education, experience, gender, and age are individual characteristics; household size (members), children, and older people of households mainly reflect households' demographic characteristics, while income, social support (financial help), distance to hazard sites, housing material, and other indicators mainly reflect characteristics of households' livelihood assets. It is worth noting that geological hazards are often sudden onset and severe, so houses and valuable fixed assets in the households may instantly come to naught due to the shocks of geological disasters. When farming households' own abilities (incomes and deposits) are not enough to cope with external shocks, the strength of social networks is critical for resisting those shocks. In order to investigate the influences of social networks on households' willingness to relocate, this study uses the number of relatives and friends available for assistance when in urgent need of a large sum of money to characterize the strength of their social networks.

\subsubsection{The Models}

Research methods in this study include a word reliability test, principal component analysis, efficacy coefficient analysis, correlation analysis, and ordinal logistic regression. Among them, the use of the word reliability test, principal component analysis, and efficacy coefficient method mainly refers to the research of Xu et al. (2016) and Zhang et al. (2013). Because the dependent variable (relocation willingness) is an ordinal categorical variable, the ordinal logistic regression model was used to identify the factors that influence a household's choice of relocation.

Hypothesize $y^{*}=x^{\prime} \beta+\varepsilon\left(y^{*}\right.$ is unobservable), and the selection rules are:

$y=\left\{\begin{array}{c}0, \quad \text { if } y^{*} \leq r_{0} \\ 1, \quad \text { if } r_{0} \leq y^{*} \leq r_{1} \\ 2, \quad \text { if } r_{1} \leq y^{*} \leq r_{2} \\ \cdots \cdots \cdots \\ J, \quad \text { if } r_{J-1} \leq y^{*}\end{array}\right.$

Wherein, $\quad r_{0}<r_{1}<r_{2}<\cdots<r_{J-1}$ are solve-for parameters, named as cutoff points.

Hypothesize $\varepsilon \sim N(0,1)$, then:

$$
\begin{array}{r}
P(y=0 \mid x)=P\left(y^{*} \leq r_{0} \mid x\right)=P\left(\varepsilon \leq r_{0}-x^{\prime} \beta \mid x\right)=\Phi\left(r_{0}-x^{\prime} \beta\right) \\
P(y=1 \mid x)=P\left(r_{0} \leq y^{*} \leq r_{1} \mid x\right)=\Phi\left(r_{1}-x^{\prime} \beta\right)-\Phi\left(r_{0}-x^{\prime} \beta\right) \\
P(y=2 \mid x)=P\left(r_{2} \leq y^{*} \leq r_{1} \mid x\right)=\Phi\left(r_{2}-x^{\prime} \beta\right)-\Phi\left(r_{1}-x^{\prime} \beta\right) \\
\ldots \ldots \ldots \\
P(y=J \mid x)=P\left(r_{J} \leq y^{*} \leq r_{J-1} \mid x\right)=1-\Phi\left(r_{J-1}-x^{\prime} \beta\right)
\end{array}
$$

According to the above formula, the sample likelihood function can be written, and then the maximum likelihood 
Table 1 Sense of place measurement

\begin{tabular}{|c|c|c|c|c|}
\hline $\begin{array}{l}\text { Entry } \\
\text { Code }\end{array}$ & Dimension & Item $^{\mathrm{a}}$ & Mean & $\mathrm{SD}^{\mathrm{b}}$ \\
\hline A1 & \multirow[t]{4}{*}{ Place identity } & I do not want to move from here, because I am used to the lifestyle here & 3.97 & 0.98 \\
\hline $\mathrm{A} 2$ & & $\begin{array}{l}\text { I am afraid of the disaster, but I still do not want to move away from here, because my roots are } \\
\text { here }\end{array}$ & 3.90 & 1.12 \\
\hline A3 & & I do not think I can be separated from the village and the people in the village & 3.72 & 1.08 \\
\hline A4 & & I never thought that I would move out of the village and live in other places & 3.33 & 1.31 \\
\hline A5 & \multirow{3}{*}{$\begin{array}{l}\text { Place } \\
\text { dependence }\end{array}$} & I feel proud of living in this village & 3.59 & 1.10 \\
\hline A6 & & Compared with other places, living in this village makes me feel more satisfied & 3.72 & 1.03 \\
\hline A7 & & My love for this village is deeper than that for anywhere else & 3.74 & 1.01 \\
\hline A8 & \multirow{3}{*}{$\begin{array}{l}\text { Place } \\
\quad \text { attachment }\end{array}$} & When going out, I always think of the village where I live & 4.32 & 0.73 \\
\hline A9 & & Unless going out to do some errands, I usually prefer to stay in the village & 4.06 & 0.79 \\
\hline A10 & & I feel that I can really be myself in the village & 4.27 & 0.75 \\
\hline
\end{tabular}

a $1=$ totally agree, $2=$ agree, $3=$ neutral, $4=$ disagree, $5=$ totally disagree

b $S D$ standard deviation

Table 2 Definition and descriptive statistics of the variables in the model

\begin{tabular}{|c|c|c|c|c|}
\hline Category & Variable & Measure & Mean & SD \\
\hline $\begin{array}{l}\text { Dependent } \\
\text { variable }\end{array}$ & Willingness & Household relocation willingness when hearing government relocation order ${ }^{a}$ & 3.56 & 1.36 \\
\hline \multirow[t]{5}{*}{ Risk perception } & Probability & Scores for perception of the possibility of a landslide (1-100) & 51.62 & 17.36 \\
\hline & Worry & Scores for worry about landslides $(1-100)$ & 73.12 & 15.39 \\
\hline & Unknown & Scores for perception of the unknown of a landslide (1-100) & 58.67 & 17.70 \\
\hline & Controllability & Scores for perception of controllability in a landslide (1-100) & 52.26 & 18.19 \\
\hline & Threat & Scores for perception of threat of a landslide (1-100) & 62.14 & 14.96 \\
\hline \multirow[t]{3}{*}{ Sense of place } & $\begin{array}{l}\text { Place } \\
\text { dependence }\end{array}$ & Scores for place dependence of farming households $(1-100)$ & 59.68 & 17.53 \\
\hline & Place identity & Scores for place identity of farming households (1-100) & 67.81 & 15.27 \\
\hline & Place attachment & Scores for place attachment of farming households $(1-100)$ & 69.88 & 16.52 \\
\hline \multirow{4}{*}{$\begin{array}{l}\text { Individual } \\
\text { Characteristics }\end{array}$} & Education & Years of education (year) & 4.98 & 3.26 \\
\hline & Experience & Whether a landslide has been experienced $(0=$ no, $1=$ yes $)$ & 0.88 & 0.33 \\
\hline & Gender & Gender $(0=$ male, $1=$ female $)$ & 0.36 & 0.48 \\
\hline & Age & Age (year) & 57.66 & 10.82 \\
\hline \multirow{9}{*}{$\begin{array}{l}\text { Household } \\
\text { characteristics }\end{array}$} & Income & Family cash income $\left(\right.$ Yuan $\left.^{\mathrm{b}}\right)$ & $44,223.99$ & $55,541.70$ \\
\hline & Financial help & Number of persons available for assistance when in urgent need of money & 4.63 & 3.28 \\
\hline & Loss & Whether there is economic loss from a landslide $(0=$ no, $1=$ yes $)$ & 0.68 & 0.47 \\
\hline & Distance & Distance to the hazard site $(<10 \mathrm{~m}=1$, else $=0)$ & 0.26 & 0.44 \\
\hline & Information & $\begin{array}{l}\text { Communication channels to obtain landslide information }(1=\text { only from } \\
\text { oneself or relatives and friends, } 2=\text { only from government or media, } \\
3=\text { from both } 1 \text { and } 2)\end{array}$ & 1.59 & 0.78 \\
\hline & Member & Number of family members & 4.21 & 1.67 \\
\hline & Child & Children $<18(0=$ no, $1=$ yes $)$ & 0.59 & 0.49 \\
\hline & Old & Older people $>65(0=$ no, $1=$ yes $)$ & 0.44 & 0.50 \\
\hline & Housing material & Housing material $(1=$ concrete, else $=0)$ & 0.77 & 0.42 \\
\hline
\end{tabular}

a 1 = strongly unwilling, $2=$ unwilling, $3=$ neutral, $4=$ willing, $5=$ strong willing

b 1 USD $=6.19$ Yuan (at the time of the study) 
estimators are obtained. Assuming that the residual follows logic distribution, the ordered logit model can then be obtained. Wherein, $y$ is the dependent variable, referring to relocation willingness of farming households, and $x$ is the independent variable, including individual characteristics, household characteristics, risk perception, and sense of place. Modeling was achieved using Stata 11.0.

\section{Results}

This study focused on the relationship of farming households' sense of place to their relocation willingness in a landslide-threatened impoverished area. We first detail the measurement results of sense of place, and then conduct the descriptive statistical analysis on the model variables. Finally, the results of the correlations between variables and the results of the econometric models are described.

\subsection{Measurement Result of Sense of Place}

The specific measurement indicators of sense of place are the 1-5 type Likert scale, so it is necessary to carry out the reliability test of the items before the principal component analysis is conducted, and in the case of passing the reliability test, the principal component analysis should be conducted. Using Cronbach's alpha to test the reliability of place identity, place dependence, place attachment, and sense of place measurements, the total scales are 0.75 , $0.82,0.74$, and 0.86 , respectively, which are within the acceptable range and indicate that these measurements are applicable for subsequent analysis. The principal component analysis result indicates that the Kaiser-Meyer-Olkin measure of sampling adequacy is 0.86 ; the $p$ value of Bartlett's test of sphericity is less than 0.00; and three factors account for $64.8 \%$ of the variance. This implies that the vocabulary entry is suitable for variable analysis. Table 3 shows that principal components extraction followed by varimax rotation identified the three hypothesized dimensions of place dependence, place identity, and place attachment. These three dimensions are the same as what was obtained by Jorgensen and Stedman's (2001) classic research. Subsequently, this study further applies the efficiency coefficient analysis method and transfers the score for respective variables into centesimal system points (Table 3).

\subsection{Descriptive Statistics of the Variables}

Table 2 shows descriptive statistics analysis results of the variables involved in the model. For risk perception, the score of worry ranks first and that of probability ranks last; for sense of place, the mean score of the three variables (place dependence, place identity, and place attachment) are 59.68, 67.81, and 69.88, respectively; for individual characteristics, $36 \%$ of the interviewees were female, the average age of all interviewees was 57.66, and the average educational level was 4.98 years. Moreover, $88 \%$ of the interviewees had experienced landslides. For household characteristics, $26 \%$ of the households are located within the red zone of a landslide threat area, and $68 \%$ had experienced economic loss due to landslides. The average family cash income was RMB 44,223 Yuan per annum. Moreover, $59 \%$ and $44 \%$ of the households have children and older people, respectively. The major information channels for landslide warnings are relatives, friends, or the government. About $77 \%$ of the houses are built from concrete (Table 2).

\subsection{Model Results}

Table 4 shows the correlations between study variables, while Table 5 shows the result of the model estimation for the relocation willingness of farming households. Collinearity diagnostics and tolerance statistics were used to diagnose potential multicollinearity problems. No evidence of multicollinearity was found in the data. To avoid the heteroscedasticity of the independent variable influencing the results, we used robust standard errors.

In order to test the robustness of variables in the models, we constructed 7 models. Among them, Model 1-Model 3 respectively indicate the results of correlations between sense of place, risk perception, as well as individual characteristics and household characteristics and farmers' willingness to relocate. Based on Model 1, Model 5-Model 7 are the regression results of gradually adding risk perception and respondents' individual characteristics and household characteristics. As shown in Table 5, except for Model 3, all models are overall significant at the 0.05 level (Prob $<0.05)$. The variation of the relocation willingness that the independent variables can explain is between $1 \%$ (Model 3) and 25\% (Model 7).

With regard to sense of place, in Models 1 and 7, place identity and place dependence both have significant negative coefficients in predicting household relocation willingness, which is consistent with hypothesis $\mathrm{H} 1$. The results indicate that the higher the scores in residents' place identity and place dependence, the less strong their relocation willingness is. Specifically, in Model 7, when everything else remains constant, every one unit increase in place identity and place dependence corresponds to an average decrease in willingness to relocate by 0.02 and $0.02\left(0.02=1-\mathrm{e}^{-0.02}\right)$, respectively. Place attachment has a nonsignificant regression coefficient, which is inconsistent with hypothesis H1. Overall, the scales 
Table 3 Component matrixes for respective components of sense of place after rotation

\begin{tabular}{llll}
\hline Items & Components & & \\
\cline { 2 - 4 } & Place identity & Place dependence & Place attachment \\
\hline A1 & $\mathbf{0 . 8 0}$ & 0.10 & 0.27 \\
A2 & $\mathbf{0 . 7 7}$ & 0.20 & 0.23 \\
A3 & $\mathbf{0 . 5 4}$ & 0.46 & 0.16 \\
A4 & $\mathbf{0 . 7 0}$ & 0.25 & -0.08 \\
A5 & 0.18 & $\mathbf{0 . 7 8}$ & 0.14 \\
A6 & 0.24 & $\mathbf{0 . 8 6}$ & 0.23 \\
A7 & 0.21 & $\mathbf{0 . 8 1}$ & 0.16 \\
A8 & 0.07 & 0.07 & $\mathbf{0 . 8 3}$ \\
A9 & 0.18 & 0.19 & $\mathbf{0 . 7 8}$ \\
A10 & 0.16 & 0.37 & $\mathbf{0 . 5 4}$ \\
Eigenvalue & 1.19 & 4.30 & 1.05 \\
Explained variance & $22.14 \%$ & $24.27 \%$ & $18.41 \%$ \\
Cumulative variance & $\mathbf{2 2 . 1 4 \%}$ & $\mathbf{4 6 . 4 1 \%}$ & $\mathbf{6 4 . 8 2 \%}$ \\
Cronbach $\alpha$ & 0.75 & 0.82 & 0.74 \\
\hline Varimax & & &
\end{tabular}

Varimax rotation was used

In each component, the bold numbers represent the component is mainly composed by the corresponding items

measuring sense of place accounted for little variance in household relocation willingness (Pseudo $R^{2}=0.03$ ).

As for risk perception, probability and threat both have significant negative regression coefficients, while controllability has a significant positive regression coefficient. These results are consistent with hypothesis $\mathrm{H} 2$. The results indicate that when residents perceive higher disaster risks and larger threats to them, their relocation willingness will be stronger. Specifically, in Model 7, when everything else remains constant, every one unit increase in probability and threat corresponds to an average increase in willingness to relocate by $0.09\left(0.09=\mathrm{e}^{0.09}-1\right)$ and $0.06(0.06=$ $\left.\mathrm{e}^{0.06}-1\right)$, respectively; every one unit increase in controllability corresponds to an average decrease in willingness to relocate by $0.03\left(0.03=1-\mathrm{e}^{-0.03}\right)$. Worry and fear of the unknown have no significant relationship to household relocation willingness, which is inconsistent with hypothesis H2. A possible reason is that farmers believe in their luck, thinking the possibility of risks affecting them is very small. Hence, they are reluctant to relocation even though they have concerns about the disasters.

Even though certain aspects of sense of place and risk perception are significantly related with residents' relocation willingness, by comparing $R^{2}$ in Model 1 and Model 2, it can be seen that compared to sense of place, risk perception is seven times as powerful a predictor of relocation willingness.

Surprisingly, inconsistent with hypothesis H3, gender, age, education, and experience have no significant coefficient on household relocation willingness. With regard to household characteristics, consistent with hypothesis $\mathrm{H} 4$, income, social support (financial help), and loss have significant coefficients on household relocation willingness, while inconsistent with hypothesis $\mathrm{H} 4$, distance to hazard, household size, children, older people, and housing material have no significant coefficients on household relocation willingness. The results for source of information are not robust. Specifically, farmers who suffer from landslide impacts and have higher incomes show stronger relocation willingness; those who have a larger number of people to turn to in the event of urgent need of money, show less relocation willingness (see Table 4 and Table 5).

\section{Discussion}

By examining a case in a developing country context and the relationship of farming households' sense of place to their relocation willingness, this research is a pilot study to explore the relationship of sense of place to the willingness to relocate of farming households in a landslide-threatened impoverished area. The results show that households with higher scores of place identity and place dependence are less willing to relocate, whereas place attachment has no significant relationship to household relocation willingness. Villages (places) not only provide farming households with their residences and livelihood resources (land), but also provide the space for daily life contacts between farming 


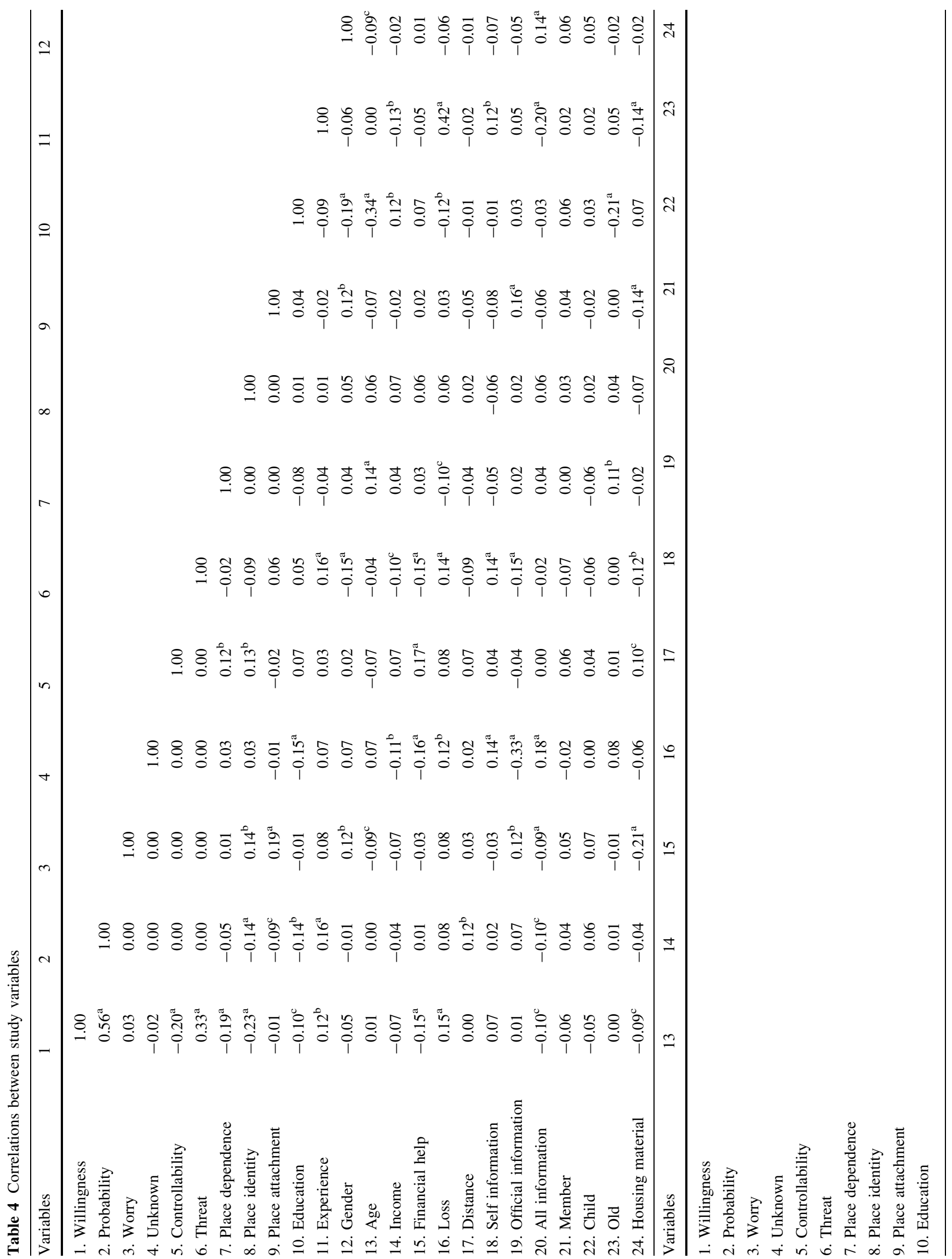




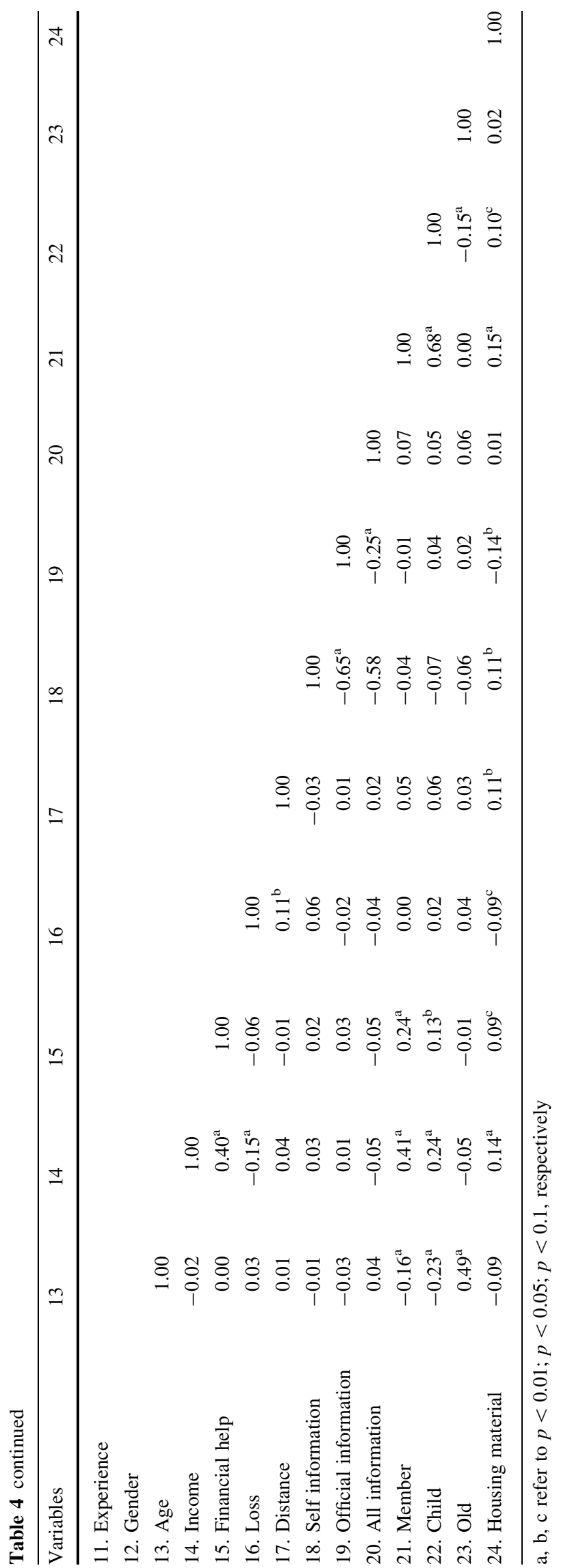

households and their neighbors. The long-term interaction between farming households and places (villages) means that farming households are deeply rooted in their villages and form a strong sense of identity and belonging (dependence) with the village (they believe that their "roots" are in the village). This strong sense of identity and dependence can weaken household willingness to relocate. As an older respondent said, "the traditional idea of 'staying in bed even during illness and staying in my hometown until natural death' has been deeply rooted in my bones. Even facing the threat of landslides, I don't want to move out of here, because my ancestors lived here, and my roots are here."

Consistent with the results of other studies (Baker 1991; Whitehead et al. 2000; Stein et al. 2010; Huang et al. 2012), risk perception is a primary factor in disaster relocation decision making. However, not all aspects of risk perception have a significant relationship to household evacuation/relocation willingness. For example, in some studies, potential and risk controllability have no significant relationship to household evacuation willingness (Lazo et al. 2015). In other studies, measures of perceived severity and susceptibility are significantly related to evacuation (Houts et al. 1984; Riad et al. 1999). In our study, probability, threat, and controllability have a significant relationship to household relocation willingness, but worry and fear of the unknown have no significant relationship to household relocation willingness.

The indicators of respondents' individual characteristics and household characteristics can reflect the characteristics of households' assets to a great extent, whereas these characteristics, to a large extent, are closely related to households' willingness to relocate. Specifically, the relationships of individual and household characteristics to residents' relocation willingness are consistent with the results of most studies, which do not have a unified conclusion. With regard to individual characteristics, gender, age, education, and experience have no significant relationship to household relocation willingness, which is consistent with the results of some studies (Lindell et al. 2005; Hasan et al.2011; Huang et al. 2012; Stein et al. 2013), but inconsistent with others (Whitehead et al. 2000; Bateman and Edwards 2002; Lazo et al. 2015; Lim et al. 2016). For household characteristics, income and loss both have a significant negative relationship to household relocation willingness, consistent with Bateman and Edwards' (2002) study, but inconsistent with other studies (Whitehead et al. 2000; Huang et al. 2012; Stein et al. 2013; Lazo et al. 2015). Social support has a positive significant relationship to household relocation willingness, consistent with Tierney's (2013) study, but inconsistent with Riad et al.'s (1999) study. In our study, distance to hazard, household size, children, older people, 
Table 5 Result of regression coefficient estimation for the relocation willingness of farming households

\begin{tabular}{|c|c|c|c|c|c|c|c|}
\hline Variables & Model 1 & Model 2 & Model 3 & Model 4 & Model 5 & Model 6 & Model 7 \\
\hline Probability & & $\begin{array}{l}0.09 * * * \\
(0.01)\end{array}$ & & & $\begin{array}{l}0.09 * * * \\
(0.01)\end{array}$ & $\begin{array}{l}0.09 * * * \\
(0.01)\end{array}$ & $\begin{array}{l}0.09 * * * \\
(0.01)\end{array}$ \\
\hline Worry & & $\begin{array}{l}0.00 \\
(0.01)\end{array}$ & & & $\begin{array}{l}0.00 \\
(0.01)\end{array}$ & $\begin{array}{l}0.01 \\
(0.01)\end{array}$ & $\begin{array}{l}0.01 \\
(0.01)\end{array}$ \\
\hline Unknown & & $\begin{array}{l}0.00 \\
(0.01)\end{array}$ & & & $\begin{array}{l}0.00 \\
(0.01)\end{array}$ & $\begin{array}{l}0.00 \\
(0.01)\end{array}$ & $\begin{array}{l}0.00 \\
(0.01)\end{array}$ \\
\hline Controllability & & $\begin{array}{l}-0.03 * * * \\
(0.01)\end{array}$ & & & $\begin{array}{l}-0.03 * * * \\
(0.01)\end{array}$ & $\begin{array}{l}-0.03^{* * *} \\
(0.01)\end{array}$ & $\begin{array}{l}-0.03 * * * \\
(0.01)\end{array}$ \\
\hline Threat & & $\begin{array}{l}0.06^{* * *} \\
(0.01)\end{array}$ & & & $\begin{array}{l}0.06 * * * \\
(0.01)\end{array}$ & $\begin{array}{l}0.06 * * * \\
(0.01)\end{array}$ & $\begin{array}{l}0.06^{* * * *} \\
(0.01)\end{array}$ \\
\hline Place dependence & $\begin{array}{l}-0.02 * * * \\
(0.01)\end{array}$ & & & & $\begin{array}{l}-0.02 * * * \\
(0.01)\end{array}$ & $\begin{array}{l}-0.02^{* * *} \\
(0.01)\end{array}$ & $\begin{array}{l}-0.02 * * * \\
(0.01)\end{array}$ \\
\hline Place identity & $\begin{array}{l}-0.03 * * * \\
(0.01)\end{array}$ & & & & $\begin{array}{l}-0.02 * * \\
(0.01)\end{array}$ & $\begin{array}{l}-0.02 * * \\
(0.01)\end{array}$ & $\begin{array}{l}-0.02 * * * \\
(0.01)\end{array}$ \\
\hline Place attachment & $\begin{array}{l}0.00 \\
(0.01)\end{array}$ & & & & $\begin{array}{l}0.00 \\
(0.01)\end{array}$ & $\begin{array}{l}0.00 \\
(0.01)\end{array}$ & $\begin{array}{l}0.00 \\
(0.01)\end{array}$ \\
\hline Education & & & $\begin{array}{l}-0.06^{*} \\
(0.03)\end{array}$ & & & $\begin{array}{l}-0.01 \\
(0.03)\end{array}$ & $\begin{array}{l}-0.01 \\
(0.04)\end{array}$ \\
\hline Experience $^{\mathrm{b}}$ & & & $\begin{array}{l}0.55 \\
(0.37)\end{array}$ & & & $\begin{array}{l}-0.07 \\
(0.36)\end{array}$ & $\begin{array}{l}-0.40 \\
(0.39)\end{array}$ \\
\hline Gender $^{c}$ & & & $\begin{array}{l}-0.26 \\
(0.21)\end{array}$ & & & $\begin{array}{l}-0.16 \\
(0.24)\end{array}$ & $\begin{array}{l}-0.09 \\
(0.25)\end{array}$ \\
\hline Age & & & $\begin{array}{l}-0.01 \\
(0.01)\end{array}$ & & & $\begin{array}{l}0.00 \\
(0.01)\end{array}$ & $\begin{array}{l}0.00 \\
(0.01)\end{array}$ \\
\hline $\ln$ (income) & & & & $\begin{array}{l}0.17 * * \\
(0.08)\end{array}$ & & & $\begin{array}{l}0.24 * * * \\
(0.09)\end{array}$ \\
\hline Financial help & & & & $\begin{array}{l}-0.11 * * * \\
(0.03)\end{array}$ & & & $\begin{array}{l}-0.10^{* *} \\
(0.04)\end{array}$ \\
\hline $\operatorname{Loss}^{\mathrm{b}}$ & & & & $\begin{array}{l}0.56^{* *} \\
(0.22)\end{array}$ & & & $\begin{array}{l}0.58 * * \\
(0.24)\end{array}$ \\
\hline Distance $^{\mathrm{b}}$ & & & & $\begin{array}{l}-0.15 \\
(0.22)\end{array}$ & & & $\begin{array}{l}-0.26 \\
(0.23)\end{array}$ \\
\hline Official information $^{a}$ & & & & $\begin{array}{l}-0.19 \\
(0.25)\end{array}$ & & & $\begin{array}{l}-0.13 \\
(0.32)\end{array}$ \\
\hline All information ${ }^{a}$ & & & & $\begin{array}{l}-0.55 * * \\
(0.26)\end{array}$ & & & $\begin{array}{l}-0.31 \\
(0.29)\end{array}$ \\
\hline Member & & & & $\begin{array}{l}-0.02 \\
(0.09)\end{array}$ & & & $\begin{array}{l}-0.01 \\
(0.10)\end{array}$ \\
\hline Child $^{\text {b }}$ & & & & $\begin{array}{l}-0.15 \\
(0.29)\end{array}$ & & & $\begin{array}{l}-0.33 \\
(0.30)\end{array}$ \\
\hline Old $^{b}$ & & & & $\begin{array}{l}-0.06 \\
(0.21)\end{array}$ & & & $\begin{array}{l}-0.09 \\
(0.26)\end{array}$ \\
\hline Housing material $^{\mathrm{b}}$ & & & & $\begin{array}{l}-0.37 \\
(0.26)\end{array}$ & & & $\begin{array}{l}-0.09 \\
(0.28)\end{array}$ \\
\hline $\operatorname{LR} \operatorname{chi} 2\left(\chi^{2}\right)^{\mathrm{c}}$ & 25.32 & 130.45 & 7.06 & 25.97 & 164.94 & 165.69 & 221.81 \\
\hline $\operatorname{Prob}>\operatorname{chi} 2\left(\chi^{2}\right)^{\mathrm{c}}$ & 0.00 & 0.00 & 0.13 & 0.00 & 0.00 & 0.00 & 0.00 \\
\hline
\end{tabular}


Table 5 continued

\begin{tabular}{llllllll}
\hline Variables & Model 1 & Model 2 & Model 3 & Model 4 & Model 5 & Model 6 & Model 7 \\
\hline Pseudo $R^{2 \mathrm{c}}$ & 0.03 & 0.22 & 0.01 & 0.03 & 0.24 & 0.24 & 0.25 \\
\hline
\end{tabular}

Robust standard errors are in parentheses; $* * *, * *$, and * refer to $p<0.01 ; p<0.05 ; p<0.1$, respectively

${ }^{a}$ Matched with coding in Table 2, official information refers to information only from the government; all information refers to information either from relatives, friends, and the media or from the government. They both take $1=$ information only from oneself or relatives and friends as the reference group

b Binary variables take 0 corresponding category as the reference group

${ }^{c}$ LR chi2 $\left(\chi^{2}\right)$ indicates the overall significance test statistic of the model; Prob $>$ chi2 $\left(\chi^{2}\right)$ represents the significance level corresponding to the test statistic; Pseudo $R^{2}$ denotes the proportion of independent variables that can explain dependent variables

and housing material have no significant relationship to household relocation willingness. These results are inconsistent with most other studies (Bateman and Edwards 2002; Lindell et al. 2005; Peacock et al. 2005; Durage et al. 2014; Lim et al. 2016).

When farming households face the threat of landslide hazards, most of the time they are aware of the threat of disaster and want to relocate, but they also take into account the high costs of relocation, such as the construction of new houses, the loss of land security (local relocation may also increase the radius of land cultivation, leading to an increase in agricultural production costs), and the psychological costs brought by the migration (such as leaving the native place and living as a vagabond). At this point, if the government wants farming households to carry out compulsory or voluntary relocation, appropriate compensation and relocation assistance are crucial. However, from the sample villages of this study, it is found that the government always provided farming households with corresponding compensation and relocation assistance after they had suffered from disasters (especially after the houses had been damaged), to make them (voluntarily or non-voluntarily) relocate. There were few support policies for farming households who were also in the geological hazard-threatened areas but not affected yet by geological disasters. For instance, a landslide occurred in Fengjie County in 2014, and the government provided a housing subsidy of 21,000 Yuan for each household whose house was seriously damaged.

The government's compensation and relocation assistance can reduce the impact of geological disasters on farming households to a certain extent, but the recovery of the farmers' livelihoods has to rely more on their own abilities (incomes and savings) and their social networks. For example, in Fengjie County, the subsidy of 21,000 Yuan per affected household was far less than the cost of building a new house. Thus, when farming households' willingness to relocate in the face of geological disasters, especially under government's compulsory order, is discussed, government's standards for compensation and relocation assistance, households' own perception, abilities, and social networks, and other factors should be considered comprehensively. Future research should further explore this question.

\section{Conclusions and Implications}

Using statistics for farming households in a landslidethreatened area, this study established ordinal logistic regression models to explore the relationship of sense of place to the willingness to relocate of farming households. The study contributes to the literature by improving our understanding of the relationship of sense of place to the relocation willingness of farming households in geological hazard-threatened villages in rural China. The research design and results may provide a reference for future studies, especially for countries like China with vast land area and various kinds of geological disasters. The results of this study also offer some research and policy insights in the following three aspects.

First, this is a pilot study that explores the relationship of sense of place on the relocation willingness of farming households, but households' willingness to relocate is only one aspect of relocation willingness. Future research could further explore the impact of sense of place on household relocation distance and relocation time, as well as willingness and behavior in relation to returning to the source area. This research only examined residents' relocation willingness under compulsory government order. Future research may compare the differences between non-voluntary relocation, voluntary relocation, and actual relocation impacting factors. Sense of place provides a new perspective for understanding farming households' relocation behaviors (relocation willingness, distance, time, return), and can provide a basis for the development of 
corresponding policies. Furthermore, this study focused only on the impact of households' sense of place on their relocation willingness in landslide threat areas. There is also a need to further verify whether the impacts of sense of place in hazard threat areas with different types of geological hazards are the same, and a cross-cultural comparative study could be carried out.

Second, China is in a transition period, and the rapid development of towns and a large number of young migrant workers may result in farming households changing their consciousness-the traditional idea of "falling leaves return to their roots" may fade in the younger generation, while the means of maintaining family livelihoods are also changing. Some farming households have gradually broken away from the limits of land that provides sustainable livelihoods, and are aware of the threat of geological disasters, carrying out spontaneous relocation. Therefore, it is necessary to conduct some targeted research on this part of the group and explore the relationship of farming households' livelihoods, sense of place, and disaster risk perception on their relocation willingness in the context of numerous migrant workers, so as to provide the basis for effective guidance of farming household relocation in geological hazard-threatened areas. In addition, in this study, the factors affecting farming households' willingness to relocate are mostly focused at the individual and household level, and rarely deal with the community level. A multifaceted and tailored approach to both individuals and communities is needed.

Third, in addition to academic inspiration, the research results also have some policy implications. For example, in our study, the results of source of information are not robust. There are no significant differences in relocation willingness between farming households obtaining information from official channels and those receiving information from friends and relatives. This suggests that the government should pay greater attention to the authenticity and authority of information in the concrete implementation of disaster preparedness and mitigation policies, to ensure that information is accurately delivered to farming households. It is necessary to pay attention to guiding the transmission of personal information, especially avoiding the spread of misleading information. Though the results show that place identity and place dependence have a significant relationship to household relocation willingness, however, by comparing the $R^{2}$ in Model 1 and Model 2, risk perception is seven times as powerful a predictor of relocation willingness than sense of place. This finding indicates that when the government makes relocation policies, especially compulsory relocation policies, they should pay attention to improving residents' risk perception level so as to let them realize the possibility and threats of the disasters in order to reduce the friction and conflicts between governments and farmers. At the same time, the government can provide some places that may foster a "sense of place" in resettlement areas, thereby reducing households' problems with adaptation after relocation.

Acknowledgements We gratefully acknowledge the financial support from the STS Program of the Chinese Academy of Sciences (KFJ-SW-STS-175); the National Natural Science Foundation of China (Grant No. 41401198); the West Light Foundation of the Chinese Academy of Sciences (Y5R2080080); the Youth Talent Team Program of the Institute of Mountain Hazards and Environment, the Chinese Academy of Sciences (SDSQB-2015-01), and the Youth Innovation Promotion Association, the Chinese Academy of Sciences (2016332). The authors also extend great gratitude to the anonymous reviewers and editors for their helpful review and critical comments, which have led to significant improvement to the early version of the manuscript.

Open Access This article is distributed under the terms of the Creative Commons Attribution 4.0 International License (http://crea tivecommons.org/licenses/by/4.0/), which permits unrestricted use, distribution, and reproduction in any medium, provided you give appropriate credit to the original author(s) and the source, provide a link to the Creative Commons license, and indicate if changes were made.

\section{References}

Adeola, F.O. 2008. Katrina cataclysm: Does duration of residency and prior experience affect impacts, evacuation, and adaptation behavior among survivors? Environment and Behavior 41(4): 459-489.

Alcántara-Ayala, I. 2009. Disasters in Mexico and Central America: A little bit more than a century of natural hazards. Developments in Earth Surface Processes 13(13): 75-97.

Baker, E.J. 1991. Hurricane evacuation behavior. International Journal of Mass Emergencies and Disasters 9(2): 287-310.

Bateman, J., and B. Edwards. 2002. Gender and evacuation: A closer look at why women are more likely to evacuate for hurricanes. Natural Hazards Review 3(3): 107-117.

Burnside, R., D.S. Miller, and J.D. Rivera. 2007. The impact of information and risk perception on the hurricane evacuation decision-making of greater New Orleans residents. Sociological Spectrum 27(6): 727-740.

Cao, M.T., D.D. Xu, F.T. Xie, E.L. Liu, and S.Q. Liu. 2016. The influence factors analysis of households' poverty vulnerability in southwest ethnic areas of China based on the hierarchical linear model: A case study of Liangshan Yi Autonomous Prefecture. Applied Geography 66(1): 144-152.

Carroll, B., H. Morbey, R. Balogh, and G. Araoz. 2009. Flooded homes, broken bonds, the meaning of home, psychological processes and their impact on psychological health in a disaster. Health \& Place 15(2): 540-547.

CRED (Centre for Research on the Epidemiology of Disasters). 2015. EM-DAT Database http://www.emdat.be/. Accessed 19 Dec 2016.

Chen, G.J., Y.P. Fang, Y. Chen, M.Y. Shen, et al. 2007. Mountain development report: Chinese mountain settlement research. Beijing: The Commercial Press (in Chinese).

Chongqing Municipal Bureau of Statistics. 2015. Chongqing Statistical Yearbook 2014. Chongqing: Chongqing Statistical Press (in Chinese). 
CNSB (China National Statistical Bureau). 2015. China yearbook of household survey in 2014. Beijing: China Statistical Press (in Chinese).

Dash, N., and H. Gladwin. 2007. Evacuation decision making and behavioral responses: Individual and household. Natural Hazards Review 8(3): 69-77.

Dow, K., and S.L. Cutter. 2000. Public orders and personal opinions: Household strategies for hurricane risk assessment. Global Environmental Change Part B: Environmental Hazards 2(4): $143-155$.

Drabek, T.E. 1986. Human system responses to disaster: An inventory of sociological findings. New York: Springer.

Durage, S.W., L. Kattan, S.C. Wirasinghe, and J.Y. Ruwanpura. 2014. Evacuation behaviour of households and drivers during a tornado. Natural Hazards 71(3): 1495-1517.

Eyles, J. 1985. Senses of place. Warrington, UK: Silverbrook Press.

Flynn, J., P. Slovic, and C.K. Mertz. 1994. Gender, race, and perception of environmental health risks. Risk Analysis 14(6): $1101-1108$.

Gaillard, J.C. 2008. Alternative paradigms of volcanic risk perception: The case of Mt. Pinatubo in the Philippines. Journal of Volcanology and Geothermal Research 172(3-4): 315-328.

Geological Disaster Emergency Response Directing Center of Ministry of Land and Resources. National geological disasters bulletin in 2016. Beijing: China Statistical Press (in Chinese).

Hasan, S., S. Ukkusuri, H. Gladwin, and P. Murray-Tuite. 2011. Behavioral model to understand household-level hurricane evacuation decision making. Journal of Transportation Engineering 137(5): 341-348.

Hernández-Moreno, G., and I. Alcántara-Ayala. 2016. Landslide risk perception in Mexico: A research gate into public awareness and knowledge. Landslides 14(1): 1-21.

Houts, P.S., M.K. Lindell, T.W. Hu, P.D. Cleary, G. Tokuhata, and C.B. Flynn. 1984. Protective action decision model applied to evacuation during the three mile island crisis. International Journal of Mass Emergencies and Disasters 2(1): 27-39.

Huang, S.K., M.K. Lindell, and C.S. Prater. 2016. Who leaves and who stays? A review and statistical meta-analysis of hurricane evacuation studies. Environment and Behavior 48(8): 991-1029.

Huang, S.K., M.K. Lindell, C.S. Prater, H.C. Wu, and L.K. Siebeneck. 2012. Household evacuation decision making in response to hurricane Ike. Natural Hazards Review 13(4): 283-296.

Jorgensen, B.S., and R.C. Stedman. 2001. Sense of place as an attitude: Lakeshore property owners' attitudes toward their properties. Journal of Environmental Psychology 21(3): $233-248$.

Kang, J.E., M.K. Lindell, and C.S. Prater. 2007. Hurricane evacuation expectations and actual behavior in Hurricane Lili. Journal of Applied Social Psychology 37(4): 887-903.

Kaniasty, K., and F.H. Norris. 1995. In search of altruistic community: Patterns of social support mobilization following Hurricane Hugo. American Journal of Community Psychology 23(4): 447-477.

Kiecolt, K.J., and J.M. Nigg. 1982. Mobility and perceptions of a hazardous environment. Environment and Behavior 14(2): $131-154$

Lazo, J.K., A. Bostrom, R.E. Morss, J.L. Demuth, and H. Lazrus. 2015. Factors affecting hurricane evacuation intentions. Risk Anaylysis 35(10): 1837-1857.

Lazo, J.K., D.M. Waldman, B.H. Morrow, and J. Thacher. 2010. Household evacuation decision making and the benefits of improved hurricane forecasting: Developing a framework for assessment. Weather and Forecasting 25(1): 207-219.
Lim, M.B., H.R. Lim, M. Piantanakulchai, and F.A. Uy. 2016. A household-level flood evacuation decision model in Quezon City, Philippines. Natural Hazards 80(3): 1539-1561.

Lindell, M.K., J.C. Lu, and C.S. Prater. 2005. Household decision making and evacuation in response to hurricane Lili. Natural Hazards Review 6(4): 171-179.

Lindell, M.K., and R.W. Perry. 2012. The protective action decision model: Theoretical modifications and additional evidence. Risk Analysis 32(4): 616-632.

Long, H.L., and J. Zou. 2010. Farmland destroyed by natural hazards in China: Spatio-temporal pattern and integrated prevention and treatment system. Disaster Advances 3(4): 592-597.

Mileti, D.S., T. Drabek, and J.E. Haas. 1975. Human systems in extreme environments. Boulder, $\mathrm{CO}$ : University of Colorado Institute of Behavioral Science.

Mishra, S., S. Mazumdar, and D. Suar. 2010. Place attachment and flood preparedness. Journal of Environmental Psychology 30(2): $187-197$.

Paton, D. 2001. Responding to hazard effects: Promoting resilience and adjustment adoption. Australian Journal of Emergency Management 16(1): 47-52.

Peacock, W.G., S.D. Brody, and W. Highfield. 2005. Hurricane risk perceptions among Florida's single family homeowners. Landscape and Urban Planning 73(2-3): 120-135.

Peng, L., L. Lin, S.Q. Liu, and D.D. Xu. 2017. Interaction between risk perception and sense of place in disaster-prone mountain areas: A case study in China's Three Gorges Reservoir Area. Natural Hazards 85(2): 777-792.

Perry, R.W. 1979. Evacuation decision-making in natural disasters. Mass Emergencies 4(1): 25-38.

Perry, R.W., M.K. Lindell, and M.R. Greene. 1981. Evacuation planning in emergency management. Lexington, MA: Heath Lexington Books.

Porter, R.R. 2015. Looking homeward: Place attachment and forced relocation. Dissertations \& Theses. Pacifica Graduate Institute, Carpinteria, USA.

Riad, J.K., F.H. Norris, and R.B. Ruback. 1999. Predicting evacuation in two major disasters: Risk perception, social influence, and access to resources. Journal of Applied Social Psychology 29(5): 918-934.

Slovic, P. 1987. Perception of risk. Science 236(4799): 280-285.

Stein, R., B. Buzcu-Guven, L. Dueñas-Osorio, D. Subramanian, and D. Kahle. 2013. How risk perceptions influence evacuations from hurricanes and compliance with government directives. Policy Studies Journal 41(2): 319-342.

Stein, R.M., L. Dueñas-Osorio, and D. Subramanian. 2010. Who evacuates when hurricanes approach? The role of risk, information, and location. Social Science Quarterly 91(3): 816-834.

Tierney, K. 2013. "Only connect!" Social capital, resilience, and recovery. Risk, Hazards and Crisis in Public Policy 4(1): 1-5.

Tobin, G.A., and L.M. Whiteford. 2002. Community resilience and volcano hazard: The eruption of Tungurahua and evacuation of the faldas in Ecuador. Disasters 26(1): 28-48.

Tobin, G.A., L.M. Whiteford, E.C. Jones, A.D. Murphy, S.J. Garren, and C.V. Padros. 2011. The role of individual well-being in risk perception and evacuation for chronic vs. acute natural hazards in Mexico. Applied Geography 31(2): 700-711.

Trumbo, C., M.A. Meyer, H. Marlatt, L. Peek, and B. Morrissey. 2014. An assessment of change in risk perception and optimistic bias for hurricanes among Gulf coast residents. Risk Analysis 34(6): 1013-1024.

Tuan, Y.F. 1979. Space and place: Humanistic perspective. In Philosophy in Geography, ed. S. Gale and G. Olsson, 387-427. Dordrecht: Springer Netherlands. 
Wallace, J.W., C. Poole, and J.A. Horney. 2014. The association between actual and perceived flood risk and evacuation from hurricane Irene, Beaufort County, North Carolina. Journal of Flood Risk Management 9(2): 125-135.

Whitehead, J.C., B. Edwards, V.W. Marieke, J.R. Maiolo, K. Wilson, and K.T. Smith. 2000. Heading for higher ground: Factors affecting real and hypothetical hurricane evacuation behavior. Global Environmental Change Part B: Environmental Hazards 2(4): 133-142.

Widener, M.J., M.W. Horner, and S.S. Metcalf. 2013. Simulating the effects of social networks on a population's hurricane evacuation participation. Journal of Geographical Systems 15(2): 193-209.

Wilmot, C.G., and B. Mei. 2004. Comparison of alternative trip generation models for hurricane evacuation. Natural Hazards Review 5(4): 170-178.

Xu, D.D., L. Peng, C.J. Su, S.Q. Liu, X.X. Wang, and T.T. Chen. 2016. Influences of mass monitoring and mass prevention systems on peasant households' disaster risk perception in the landslide-threatened Three Gorges Reservoir area, China. Habitat International 58: 23-33.

Xu, D.D., L. Peng, S.Q. Liu, C.J. Su, X.X. Wang, and T.T. Chen. 2017. Influences of migrant work income on the poverty vulnerability disaster threatened area: a case study of the Three Gorges Reservoir area, China. International Journal of Disaster Risk Reduction 22: 62-70.

Xu, D.D., J.F. Zhang, G. Rasul, S.Q. Liu, F.T. Xie, and M.T. Cao. 2015a. Household livelihood strategies and dependence on agriculture in the mountainous settlements in the Three Gorges reservoir area, China. Sustainability 7(5): 4850-4869.

Xu, D.D., J.F. Zhang, F.T. Xie, S.Q. Liu, and M.T. Cao. 2015b. Influential factors in employment location selection based on "push-pull" migration theory: A case study in Three Gorges reservoir area in China. Journal of Mountain Science 12(6): $1562-1581$.

Yang, H., E.F. Morgul, K. Ozbay, and K. Xie. 2016. Modeling evacuation behavior under hurricane conditions. Transportation Research Board 95th Annual Meeting, 10-14 January 2016, Washington DC, USA.

Yao, H., and Z. Xu. 2013. Development Report for West China in 2012. Beijing: Social Sciences Academic Press (in Chinese).

Zhang, Y.W., S.C. Li, F.Q. Meng, and R.Z. Zhao. 2013. Geoenvironment evaluation of damaged mountains based on efficacy coefficient method in Jinan, China. Advanced Materials Research 838-841: 2503-2506. 